\title{
Systematic reviews in theory and practice for library and information studies
}

Sue F. Phelps, Nicole Campbell

\begin{abstract}
This article is about the use of systematic reviews as a research methodology in library and information studies (LIS). Systematic reviews attempt to gather all of the research on a given topic in order to answer a specific question. They have been used extensively in the health care field and have more recently found their way into the social sciences, including librarianship. Examples of the use of systematic reviews in LIS illustrate the benefits and challenges to using this methodology. Included is a brief description of how to conduct a review and a reading list for further information.
\end{abstract}

\section{Introduction}

Systematic reviews are used in many disciplines to review and analyse research. Perhaps the most widely-known are from the health sciences fields, where summarizing and synthesizing vast quantities of research to inform decisionmaking is essential and where the "systematic review lies at the heart of evidencebased health care" (Beverely, 2003, 65). This methodology is also used in other fields, especially in the social sciences (see the Campbell Collaboration in the Reading List), and is beginning to be seen in library and information studies (LIS). It is the goal of this paper to explore the use of systematic reviews in librarianship and discuss some benefits and challenges of systematic reviews.

\section{$1.1 \quad$ Definitions}

There are many methods for "reviewing" research. In fact, Marcia J. Grant and Andrew Booth (2009) describe fourteen different types of reviews, which differ in search method, appraisal of included articles, type of synthesis, and type of

\section{Authors}

Sue F. Phelps is a reference librarian at Washington State University Vancouver and is interested in assessment for evidence based decision making in all aspects of academic librarianship.

Nicole Campbell is Interim Library Director at Washington State University Vancouver and is interested in user-centred services, usability and assessment.

Email: asphelps@vancouver.wsu.edu 
analysis. Systematic reviews are distinguished from other review types by adhering to a methodical and transparent process.

The Campbell Collaboration defines systematic reviews in this way:

The purpose of a systematic review is to sum up the best available research on a specific question. This is done by synthesizing the results of several studies.

A systematic review uses transparent procedures to find, evaluate and synthesize the results of relevant research. Procedures are explicitly defined in advance, in order to ensure that the exercise is transparent and can be replicated. This practice is also designed to minimize bias.

Studies included in a review are screened for quality, so that the findings of a large number of studies can be combined. Peer review is a key part of the process; qualified independent researchers control the author's methods and results.

(Campbell Collaboration, n.d.)

This emphasis on explicit, predefined procedures and on identifying all relevant research make systematic reviews a rigorous, replicable research methodology. Also, it is important for more than one person to be involved in each step of the systematic review to catch problems and minimize bias. Authors of the Cochrane Collaboration Open Learning Material for Reviewers (2002) contend that even experts can have preconceived ideas about topics that might affect whether they include or exclude a study, so the best course is to involve reviewers with different backgrounds in making these judgements. Reviewers also need to accept that they have biases and to listen to other reviewers' opinions (Alderson and Green, 2002).

\section{Advantages of systematic reviews}

Greenhalgh $(1997,363)$ states the following advantages of systematic reviews:

- $\quad$ explicit methods limit bias in identifying and rejecting studies;

- conclusions are more reliable and accurate because of methods used;

- large amounts of information can be assimilated quickly by healthcare providers, researchers, and policymakers;

- delay between research discoveries and implementation of effective diagnostic and therapeutic strategies may be reduced;

- results of different studies can be formally compared to establish generalizability of findings and consistency (lack of heterogeneity) of results;

- reasons for heterogeneity (inconsistency in results across studies) can be identified and new hypotheses generated about particular subgroups;

- quantitative systematic reviews (meta-analyses) increase the precision of the overall result. 
These same advantages apply to library studies, but, with the exception of health sciences librarianship, systematic reviews have been uncommon in library and information studies, though the profession is beginning to use them outside of the medical setting. In her article written to introduce librarians to systematic reviews, K. Ann McKibbon (2006) lists five areas in which systematic reviews are useful: when too much information is available; when too little information is available; to resolve discrepancies; to provide teaching and training materials; and to plan for new research. In library studies, there are examples of how systematic reviews are currently, or could be, used for these purposes.

\subsection{Uses of systematic reviews in LIS}

In their 2006 systematic review of effective methods for teaching information literacy skills, Denise Koufogiannakis and Natasha Wiebe retrieved 4,356 articles from 15 databases in their initial search of the literature on this topic. Certainly, this is too much information for the teaching librarian to sort through in order to plan for his/her next bibliographic instruction. However, because the reviewers synthesized the information from the studies that was relevant to their research questions we can all benefit from their work and use the wisdom of the many librarians who have done research in this area. It is in this synthesis of large amounts of information where systematic reviews can facilitate a shorter time between research and practice, as Greenhalgh (1997) suggests.

On the other hand, a systematic review of topics that have not been addressed in the literature in abundance, but are recurring in the profession, could provide a comprehensive view of that subject over time. Although this type of review is most common in healthcare (McKibbon, 2006), it could also apply to librarianship. For example, one topic that has not been covered in depth is that of burn out in teaching librarians. Whether that is publication bias or the reluctance of librarians to address the issue in the literature, there is a paucity of information about how librarians are addressing an important problem. A search by the authors in Library, Information Science and Technology Abstracts for burnout and librarians resulted in 46 retrievals dating back to 1980. Add teaching to the search and retrievals fell to ten. For a library supervisor, it would be useful to have a synthesis of the history of burnout in the field and what has been tried to prevent or address the issue with teaching librarians.

Systematic reviews to resolve discrepancies collect all of the information on a controversial topic and "help uncover the truth about hotly debated issues" (McKibbon, 2006, 206) or describe each side of the topic in detail. For instance, a current topic that is not universally agreed upon in the field of academic library studies might be whether to support the teaching faculty in their teaching of information literacy in the classroom. This would mean that teaching librarians would teach the faculty how to incorporate information literacy into their curriculum which would reduce the number of instruction sections taught by librarians. Many questions arise when considering this idea and opinions certainly vary. A systematic review could bring together the pros, cons, and 
challenges in a "train the trainer" program and aid in decision making for individual academic communities.

McKibbon also finds systematic reviews useful to provide teaching and training materials for graduate students because a thorough review of the literature can "cover the research and general aspects of a specific topic in greater depth than one would find in a textbook chapter" (McKibbon, 2006, 206). This would particularly apply to current developments in standard library issues as well as recent developments in librarianship.

Finally, one of the ways that systematic reviews could be most helpful to librarians at this time is to analyse research that has been done in librarianship, to identify the gaps, and to aid the profession in planning for new research. In their systematic review of literature across disciplines about librarian-faculty relationships, Phelps and Campbell (2012) observed that only 77 of the 304 articles that were analysed (25\%) reported on actual research projects. Of the research articles only two research projects actually studied the relationship itself. These results point out the lack of research that has been published on the librarian-faculty relationship, an issue very important to academic librarians.

Systematic reviews are highly compatible with the growing practice of evidencebased librarianship defined as:

a process for integrating the best available scientifically-generated evidence into making important decisions. EBL seeks to combine the use of the best available research evidence with pragmatic perspective developed from working experiences in librarianship. EBL actively supports increasing the proportion of more rigorous applied research studies so the results can be available for making informed decisions.

(Eldredge, 2006, 342)

Here Eldredge (2006) points out the important roles of both the practitioner who uses information for decision making and the researchers who produce the evidence. As previously noted, systematic reviews are a very useful way to compile information and point out the gaps in library research. Koufogiannakis and Crumley (2006) discuss issues to consider in using library literature for evidence based practice. They state that "We have many articles; we do not have a body of evidence" (Koufogiannakis and Crumley, 2006, 325). They quote a content analysis done by Koufogiannakis et al. from 2003 in which they found that only $30 \%$ of the articles studied could actually be classified as research, and of those, "only $21 \%$ were comparative studies, cohort studies, randomized controlled trials, controlled trials, or systematic reviews" (Koufogiannakis and Crumley, 2006, 326). They concluded that more rigorous research methods would enhance the quality of library research and library literature. 


\section{Difficulties of systematic reviews}

Systematic reviews are not without their difficulties. First, the quality of the review is dependent on the quality of the studies from which one collects the data: if reviews are to be robust the research articles they are built on must be robust as well. Similarly, if there is a lack of research on a particular topic there will be no data for a review of any type to address a research question.

Article retrieval can also present a problem if abstracts are not precise about the content of an article or if author supplied key words are too broadly applied. This lack of precision makes the extensive reading required for a systematic review even more time consuming as many more articles are retrieved than strictly address a given issue. In the systematic review of Phelps and Campbell (2012), only a fraction of the articles retrieved were about the librarian and faculty relationship though these were the search terms used in all of the disciplinary databases.

Even when retrievals are focused it is very time consuming to search, read, and synthesize the amount of information that is contained in a systematic review. Many librarians do not have the support of their employers to use work time to conduct this level of research nor wish to pursue a project of this size outside of work hours. Since good systematic reviews require the participation of more than one person, the cost in time and effort increases by the number of people involved.

Finally, though the various steps of conducting a systematic review are within the skill set of librarians, there is a learning curve to consider when the methodology is new to the researchers. Setting criteria for collection and sorting of information can be complex and data analysis is not something that is commonly taught in graduate schools of librarianship.

\section{Conducting a systematic review}

Systematic reviews need to be rigorous and thorough with a transparent and reproducible search and retrieval process. This methodical approach ensures consistency and helps to minimize bias, but can also seem overwhelming to those who are new to this method. However, appropriate planning and an understanding of the accepted procedures will help. Steps for conducting a systematic review are outlined here. More specific guidance, including detailed direction on each step, is available elsewhere for the health sciences, social sciences, and library and information science. (See recommended reading.)

\subsection{Planning}

First, it is important to plan and organize the systematic review before starting. This is essential to ensuring consistency throughout the lengthy process. By planning out the stages of the review, each part can be "completed consistently, correctly, and efficiently" and can be recorded in detail (McKibbon, 2006, 207). Referred to in the health sciences as the "review protocol", this planning stage 
includes establishing a specific research question, defining inclusion and exclusion criteria, creating a search strategy, and developing a plan for analysing and synthesizing results (Centre for Reviews and Dissemination, 2009).

Well-formed research questions are the key to successful systematic reviews. In addition to the research question, specific objectives are important for focusing the review and determining which studies to include. Precise research questions and objectives are essential because reviewers "must make a dichotomous (yes/no) decision as to whether each potentially relevant paper will be included, or, alternatively, rejected as 'irrelevant'" (Greenhalgh, 1997, 672).

In LIS, precise objectives could include specific populations or library types, such as academic libraries or undergraduate students; specific areas of LIS practice, such as information literacy or collection management; or even specific outcomes, such as higher usage of online reference tools. For example, Du Preez (2007) conducted a systematic review of engineers' information needs and information seeking behavior using the Leckie Model of Information Seeking of Professionals as a guide for assessing the data. It was an attempt to understand the "different tasks in which engineers are involved and how those tasks influence their information needs and their information seeking behavior" (Du Preez, 2007, 72).

\subsection{Inclusion and exclusion criteria}

After establishing precise research questions and objectives, the next step in a systematic review is to define criteria for which studies to include and which to exclude. The criteria "should capture all studies of interest" (Centre for Reviews and Dissemination, 2009, 10). Establishing clear and explicit criteria helps minimize selection bias later and, as McKibbon notes, helps readers "verify that studies were chosen using methods that minimize bias and determine why other studies were excluded" (McKibbon, 2006, 210). Criteria found in the literature has been as simple as Du Preez's inclusion of only "sources that reported on research regarding engineers' information use" $(2007,74)$ or as detailed as that of Li Zhang et al. when they compared computer assisted library instruction to faceto-face library instruction. Inclusion criteria included:

1. Types of Study Design: a wide range of study designs were considered for inclusion in this systematic review. These included Randomized Controlled Trials (RCTs), controlled trials, cohort studies, and case studies. Only those studies with a sample size greater than one, and in which pre-test and post-test measurements were performed were included.

2. Types of Participants: participants had to be patrons in a university, college, or other type of post-secondary education library.

3. Types of Intervention: the study described had to compare computer assisted instruction with traditional (face-to-face) instruction.

4. Types of Outcome Measures: students' information skills and affective reaction needed to be considered.

(Li Zhang et al., 2008, 479) 


\subsection{Searching}

Next, a comprehensive search for relevant studies is done with an effort to "cover all the literature" (Hemingway and Brereton, 2009, 4). Because "even the best ... search will miss important papers" (Greenhalgh, 1997, 672), multiple approaches are employed, including extensive database searching, browsing important journals and conference proceedings, citation searching of bibliographies and cited references, contacting specific organizations or researchers, and searching the Web. Research into effective search strategies in systematic reviews has highlighted the need for using a variety of approaches and that database searching alone is not sufficient for finding relevant studies (Greenhalgh and Peacock, 2005). For example, in their systematic review Li Zhang et al. supplemented extensive searching of the LISA, ERIC, and Library Literature databases with "manual searches of reference lists of included studies and the files of the authors" (2008, 479).

\subsection{Screening}

It is very likely that large numbers of studies will be identified during the search process. These will need to be screened for inclusion in the review, using the research questions/objectives and the inclusion and exclusion criteria as guidance. Initially, the title and abstract of each study is analysed and any studies that obviously do no match the inclusion criteria are dropped; it is "important to err on the side of over-inclusion" at this stage (Centre for Reviews and Dissemination, 2009, 23). When it is not clear from the title and abstract whether a study is relevant, the full study should be analysed and compared to the inclusion criteria. The goal is to make sure only relevant studies are included in the review and that irrelevant studies are removed. A clear set of inclusion criteria is essential for this step.

\subsection{Data extraction}

After screening is complete, studies that meet all inclusion criteria need to be read and reviewed. This step is called data extraction. The specific elements that need to be collected will vary for each systematic review and will be guided by the research questions and objectives. For example, in Du Preez's (2007) study of the information seeking needs and behaviors of engineers, data extraction was driven by the Leckie model that she used to determine which characteristics to look for in the literature. Similarly, the Phelps and Campbell (2012) used the elements of the Trust and Commitment Model of Relationship Marketing to determine which elements of the relationship between librarians and faculty to extract from the literature for analysis. One can also set one's own list of criteria for a qualitative study as Koufogiannakis and Wieble (2006) did for researching teaching of information literacy skills. They list 23 extraction elements that include bibliographic information, research study criteria, teaching methods and delivery.

Based on the specific elements of the review's research questions and objectives, each included study is analysed. A standard data extraction form that includes all 
elements to be collected from each study is helpful for this step and helps ensure consistency. At least two people should read and extract data from each study and "disagreements should be noted and resolved by consensus among researchers or by arbitration by an additional independent researcher" (Centre for Reviews and Dissemination, 2009, 29). After this level of detailed analysis, some studies might be excluded as irrelevant.

\subsection{Data synthesis, analysis and presentation}

Data from all relevant studies that meet inclusion criteria are then synthesized and analysed. The type of synthesis will vary depending on the data extracted from each study. If the data are similar enough across studies, it is possible to do a statistical analysis (meta-analysis), which "allows the review question to be answered by calculating a quantitative summary measure, and permits a detailed statistical exploration of other factors that may affect the review's findings" (Petticrew, 2006, 164). If there is inconsistency in the data across studies, narrative synthesis is used. Using both narrative and statistical analysis approaches in tandem "may even make for a better and more thorough review" (Petticrew, 2006, 164). For example Koufogiannakis and Wieble (2006) use both narrative and statistical analysis in their study of teaching methods for information literacy. Statistical analysis software and content analysis software may help with this step. The goal of data synthesis is to go beyond simply summarizing but to also include "an analysis of the relationships within and between studies and an overall assessment of the robustness of the evidence" (Centre for Reviews and Dissemination, 2009, 48).

Finally, the results and process of the systematic review should be reported. This step should include details of the entire review process including inclusion criteria and the search strategy: "providing the full detail of searches helps future researchers to re-run or update the searches and enables readers to evaluate the thoroughness of searching" (Centre for Reviews and Dissemination, 2009, 22). Also, problems or weaknesses with the systematic review process or the collected studies should be included in the report to ensure transparency.

\section{Conclusion}

As librarians seek to base their decision making on the best available research, systematic reviews are a useful method to gather all relevant data on a specific question and synthesize the results in a manageable report. As systematic reviews become more common, gaps and weaknesses in library literature will be revealed and areas for future research will be highlighted. The methodology is timeconsuming but the results outweigh the cost if librarians can gain the support of their institutions to pursue them. Librarians interested in considering a systematic review can refer to the reading list for further information. 


\section{Recommended Reading}

Campbell Collaboration (n.d.) What helps? What harms? Based on what evidence? Producing a review [online]. URL:

http://www.campbellcollaboration.org/systematic_reviews/index.php [accessed 2011-2012].

Centre for Reviews and Dissemination (n.d.) Systematic reviews: CRD's guidance for undertaking reviews in health care. York: University of York, Centre for Reviews and Dissemination [online]. URL:

http://www.york.ac.uk/inst/crd/SysRev/!SSL!/WebHelp/SysRev3.htm [accessed 2011-2012].

Higgins J.P.T. \& Green S. (eds.) (2011) Eldredge handbook for systematic reviews of interventions. Version 5.1.0 [online]. URL: http://www.cochranenet.org [accessed 2011-2012].

McKibbon, K.A. (2006) Systematic reviews and librarians, Library Trends, 55(1), 202-15 [online]. URL: http://www.cochrane-handbook.org [accessed 20112012].

Petticrew, M., and Roberts, H. (2006) Systematic reviews in the social sciences: a practical guide. Malden, Mass.: Blackwell.

\section{References}

Alderson, P. and Green, S. (2002) Cochrane Collaboration Open Learning Material for Reviewers [online]. URL: http://www.cochrane-net.org/openlearning/ [accessed 01.10.11].

Beverely, C. A., Booth, A. and Bath, P. A. (2003) The role of the information specialist in the systematic review process: a health information case study, Health Information and Libraries Journal 20, 65-74.

Campbell Collaboration (n.d.) What helps? What harms? Based on what evidence? Producing a review [online]. URL:

http://www.campbellcollaboration.org/systematic_reviews/index.php [accessed 2011-2012].

Centre for Reviews and Dissemination (n.d.) Systematic reviews: CRD's guidance for undertaking reviews in health care. York: University of York, Centre for Reviews and Dissemination [online]. URL: http://www.york.ac.uk/inst/crd/SysRev/!SSL!/WebHelp/SysRev3.htm [accessed 2011-2012].

Du Preez, M. (2007) Information needs and information seeking behavior of engineers: a systematic review, Mousaion 25(2), 72-94.

Eldredge, J. (2006) Evidence-based librarianship: the EBL process, Library Hi Tech 24(3), 341-354. 
Grant, M. J. and Booth, A. (2009) A typology of reviews: an analysis of 14 review types and associated methodologies, Health Information and Libraries Journal 26, 91-108.

Greenhalgh, T. (1997) How to read a paper: Papers that summarise other papers (systematic reviews and meta-analyses), British Medical Journal [online], 315(672). URL: http://www.bmj.com/content/315/7109/672.full [accessed 02.10.2011].

Greenhalgh, T. and Peacock, R. (2005) Effectiveness and efficiency of search methods in systematic reviews of complex evidence: audit of primary sources, British Medical Journal 331(7524), 1064-1065.

Hemingway, P. and Brereton, N. (2009) What is a systematic review?, What is...? series [online]. URL:

http://www.medicine.ox.ac.uk/bandolier/painres/download/whatis/Systreview.pdf [accessed 10.10.11].

Koufogiannakis, D. and Crumley,E. (2006) Research in librarianship: issues to consider, Library Hi Tech 24(3), 324-340.

Koufogiannakis, D. and Wiebe, N. (2006) Effective methods for teaching information literacy skills to undergraduate students: a systematic review, Evidence Based Library and Information Practice [online], 1(3). URL: http://ejournals.library.ualberta.ca/index.php/EBLIP/article/view/76 [accessed 15.09.2011].

McKibbon, K.A. (2006) Systematic reviews and librarians, Library Trends 55(1), 202-15.

Petticrew, M., and Roberts, H. (2006) Systematic reviews in the social sciences: a practical guide. Malden, Mass.: Blackwell.

Phelps, S. F. and Campbell, N. (2012) [untitled], Journal of Academic Librarianship [at the press].

Zhang, L., Watson, E. M. and Banfield, L. (2007) The efficacy of computerassisted instruction versus face-to-face instruction in academic libraries: a systematic review, The Journal of Academic Librarianship 33(4), 478-84.

\section{Open access and copyright}

Library and Information Research is an open access journal. A freely available copy of this paper may be downloaded from the journal's website:

http://www.cilipjournals.org.uk/lir

Copyright and associated moral rights in works published in Library and Information Research are retained by the author(s) but this paper may be used freely, with proper attribution, in educational and other non-commercial settings. 